\title{
Who Approves Fraudulence? Configurational Causes of Consumers' Unethical Judgments
}

\author{
Alexander Leischnig ${ }^{1}$ Arch G. Woodside ${ }^{2}$
}

Received: 17 February 2017/ Accepted: 8 September 2017/Published online: 5 October 2017

(C) The Author(s) 2017. This article is an open access publication

\begin{abstract}
Corrupt behavior presents major challenges for organizations in a wide range of settings. This article embraces a complexity theoretical perspective to elucidate the causal patterns of factors underlying consumers' unethical judgments. This study examines how causal conditions of four distinct domains combine into configurational causes of unethical judgments of two frequent forms of corrupt consumer behavior: shoplifting and fare dodging. The findings of fuzzy-set Qualitative Comparative Analyses indicate alternative, consistently sufficient "recipes" for the outcomes of interest. This study extends prior work on the topic by offering new insights into the interplay and the interconnected structures of multiple causal factors and by describing configurational causes of consumers' ethical evaluations of corrupt behaviors. This knowledge may support practitioners and policy makers to develop education and control approaches to thwart corrupt consumer behaviors.
\end{abstract}

Keywords Complexity theory · Configurational cause . Consumer ethics · Corrupt behavior - FsQCA

Alexander Leischnig

a.leischnig@qmul.ac.uk

Arch G. Woodside

arch.woodside@curtin.edu.au

1 School of Business and Management, Queen Mary University of London, Mile End Road, E1 4NS London, United Kingdom

2 School of Marketing, Curtin School of Business, Curtin University, Perth, WA, Australia

\section{Introduction}

A considerable body of literature on market exchanges rests on the premise that consumers act as principled, goodmannered market actors who comply with contractual terms, social norms, and legal rules. The optimistic view that all consumers behave in such a way, however, may be viewed as wishful thinking (Wirtz and Kum 2004). In fact, organizations in a variety of settings experience the dark side of some people's behaviors, that is, actions by individuals that violate generally accepted norms of conduct (Fullerton and Punj 2004) and thus cause problems for or disrupt otherwise functional exchange processes (Lovelock 2001).

The phenomenon of consumer misbehavior can take various forms ranging from verbal or physical abuse of employees to vandalism, consumer theft, or financial fraud (Fisk et al. 2010; Harris and Daunt 2013). The aggregate impact of such misbehaviors is often substantial and manifests in negative externalities for organizations, frontline employees, other consumers, and sometimes even society at large (Fullerton and Punj 2004). For example, the Global Retail Theft Barometer (2015), a survey of retailers in different business sectors in 24 countries, reports costs of $\$ 47$ billion due to customer theft (i.e., only one form of consumer misbehavior) and expenditures for loss prevention systems, such as alarm monitoring systems, safe guards and face recognition systems, that account for $1.2 \%$ of the retailers' total sales volume in 2014-2015. The substantial losses associated with consumer misbehavior and the additional costs for detection and prevention suggest that the topic has a high priority on both managers' and researchers' agendas.

Research on consumer misbehavior has evolved along three major literature streams. One literature stream 
focuses on consumer misbehavior as a summary term and develops typologies and classification schemes to categorize its multiple forms, characteristics, drivers, and inhibitors (e.g., Fisk et al. 2010; Fullerton and Punj 2004). A second literature stream takes an offender-oriented perspective and develops categories and profiles of misbehaving consumers (e.g., Cameron 1964; Daunt and Harris 2012; Fullerton and Punj 1993; Hauber 1980; Moore 1984). The third literature stream includes articles that examine specific forms of consumer misbehavior to explain their antecedents and consequences (e.g., Bellur 1981; Cox et al. 1990; Wirtz and Kum 2004; Wirtz and McColl-Kennedy 2010).

Although prior work on the topic has made important contributions to the understanding of individuals' predispositions toward misbehavior and misbehavior per se, an important, yet under-researched, issue involves the complex causality that characterizes its ethical judgment. Complex causality refers to a situation "in which an outcome may follow from several different combinations of causal conditions" (Ragin 2008, p. 23). Complex causality embraces the notions of conjunction, that is, multiple causal factors work together to produce an outcome; equifinality, that is, alternative pathways to the same outcome likely exist; and asymmetry, that is, single causal factors that relate to an outcome in one configuration may be irrelevant, or even inversely related in other configurations. These notions are relevant for psychological processes, such as ethical decision making, in particular, since in many situations the results of these processes emerge from consideration of multiple, interdependent factors.

Against this background, this article aims to advance the knowledge on consumer ethics by illuminating configurational causes underlying individuals' ethical judgments of two frequently reported types of consumer misbehavior: shoplifting and fare dodging. These types of misconduct reflect dishonest, covert, primarily financially motivated, and illicit acts, which can be classified as a subcategory of consumer misbehavior-so-called corrupt behaviors. This article makes a theoretical contribution by adopting an integrative position based on complexity theory (Byrne and Callaghan 2013; Urry 2005; Woodside 2017) that connects multiple theoretical perspectives on corrupt behaviors. This article sheds light on causal factors of four domains (i.e., deterrence, personality, norm, and sociodemographic factors) and examines causal recipes to explain consumer judgments of corrupt behaviors. By embracing a complexity theoretical turn, this article provides vision "for explicit consideration of hypotheses counter to the dominant logic of presenting one theory per study" (Woodside 2014 , p. 7). The analysis of the pattern of factors, their interrelationships, and interconnected structures offers insight into how different factors and their combinations relate to individuals' judgments of misbehaviors. This knowledge can contribute to a more fine-grained and nuanced understanding of consumer ethics by uncovering complementarity, substitution, and suppression effects between factors and, as such, by indicating tipping points for ethical dissolution (Jackson et al. 2013). It thus addresses research priorities as they have been formulated in previous studies on the topic (e.g., Vitell 2003).

To achieve these goals, this article analyzes data that come from a sample of 390 respondents from the 2000 German General Social Survey (GESIS-Leibniz Institute for the Social Sciences 2008). To analyze these data, this study employed fuzzy-set Qualitative Comparative Analysis (fsQCA; Ragin 2008), that is, a set-theoretic method based on Boolean algebra, which is useful for probing complexity theoretical propositions. FsQCA takes into account that an outcome usually depends on multiple antecedent conditions, that antecedent conditions hardly ever operate independently from each other, and that a specific antecedent condition may have positive or negative effects depending on how it combines with other antecedent conditions (Greckhamer et al. 2008).

\section{Forms of Corrupt Consumer Behavior}

The phenomenon of consumer misbehavior is subject of analysis in a variety of academic fields including such disciplines as criminology, psychology, sociology, and business research. Based on the nature of consumer misconduct, motives to perform these acts, targets, consequences, and reactions by directly and indirectly aggrieved parties, literature indicates subcategories of consumer misbehavior (Fullerton and Punj 2004). One of these subcategories is corrupt consumer behavior which includes covert, primarily economically driven consumer acts that are directed against financial assets of organizations and institutions. Corrupt behavior is criminal, violates not only ethical standards but also legal rules, and results in substantial costs for the target and oftentimes even indirectly associated actors. Typical examples of such forms of misbehavior include shoplifting and fare dodging.

Shoplifting is theft by shoppers or consumers who pretend to shop and is one of the most commonly committed crimes in modern society (Krasnovsky and Lane 1998). The significant costs from shoplifting are borne by retailers and legitimate customers who suffer from inferior retail experiences and higher prices (Cox et al. 1990). Many retailers invest heavily in security systems to prevent and minimize shoplifting. In addition, retailers charge higher prices in an attempt to offset the shrinkage due to consumer theft (Tonglet 2002). Cameron (1964) was among the first to systematically examine shoplifting in retail. Her 
typology of "boosters," that is, professional shoplifters who steal to sell, and "snitches," that is, average people who shoplift but who have no contact to criminal groups and little or no commercial intentions, has been the springboard for several subsequent studies. For example, Moore (1984) identifies five groups of shoplifters, including "impulsive shoplifters," "occasional shoplifters," "episodic shoplifters," "amateur shoplifters," and "semiprofessional shoplifters." In addition, and taking a rational choice perspective, previous work finds that shoplifters can be further classified as "rationalists," "non-rationalists," and "mixed," that is, shoplifters who differ by their level of goal orientation (Schlueter et al. 1989). Besides classifications, prior research reveals that shoplifting is likely to be influenced by a variety of factors. Causal antecedents include social/peer group pressures (Cox et al. 1990, 1993), personality traits (Babin and Babin 1996; Egan and Taylor 2010), consumers' financial situations (Moore 1984), norms (Fullerton and Punj 1993, 2004), and deterrence factors such as the likeliness of being caught (Cole 1989).

Fare dodging is a further form of corrupt behavior. In comparison with shoplifting and other forms of consumer misbehavior, fare dodging has received only limited attention in academic research. Fare dodging refers to the use of transportation systems without having a valid ticket (Hauber 1980). Such misbehavior leads to declining revenues for transportation operators and higher costs for honest passengers (Bijleveld 2007). Previous work reveals four major groups of fare dodgers covering "naive dodgers" who, for example, accidentally forget to buy a ticket while rushing into a train, "occasional dodgers" who, more consciously, but only on some occasions commit fare fraud, "calculating or political dodgers" who practice fare fraud regularly, on purpose, and with a strategy, and "cunning dodgers" who most often use transportation without paying for it (Hauber 1980). Fare dodging has been most commonly studied in criminology and transportation research with an emphasis on two primary perspectives. Opportunity-oriented studies describe situations and constellations of operational factors that may provide conditions favorable to fare dodging. These studies indicate the fare dodging depends on such factors as financial strains of offenders, lack of surveillance, or peak traveling (e.g., Smith and Clarke 2000). Deterrence-oriented studies examine the effectiveness of measures (e.g., physical entry and exit barriers, automatic fare collection systems, penalty enforcement, and control work) to enhance apprehension chances and reduce evasion rates (e.g., Clarke et al. 2010; Smith and Clarke 2000; Suquet 2010).

\section{Unethical Judgments of Corrupt Behaviors: A Complexity Theoretical Perspective}

\section{Antecedent Conditions for Unethical Judgments}

The literature on factors associated with corrupt consumer behavior and the ethical judgment thereof points to a plethora of potentially relevant causal antecedents. Based on a literature review in the disciplines of criminology, sociopsychology, and business research on shoplifting, and fare dodging, as well as consumer misbehavior and consumer ethics in general, this article sheds light on four major sets of antecedent conditions to explain attitudes toward corrupt behaviors. The sets of antecedent conditions reflect diverse theoretical viewpoints and include (1) deterrence factors (i.e., perceived likeliness of detecting shoplifting and fare dodging), (2) personality factors (i.e., chronic attitudes of opportunism and ruthlessness, and bribery and corruption), (3) norm factors (i.e., obedience to law), and (4) sociodemographic factors (i.e., gender, age, and household income).

Prior work indicates that deterrence factors may serve as useful explanations for consumers' judgments of corrupt behaviors (e.g., Cole 1989; Kallis and Vanier 1985; Kraut 1976). Deterrence research concerns "the process by which a society coerces individuals into conformity through legal sanctions" (Cole 1989, p. 108). Deterrence factors influence the teleological evaluation of acts (Hunt and Vitell 2006) by signalizing threat of punishment. Such threat comes from the perceived level of certainty of being detected and severity of punishment. Deterrence research provides contradictory findings and opinions about the effects of certainty versus severity of punishment in inhibiting criminal acts. However, criminology literature indicates that the probability of being caught has a greater deterrent impact on crime rates than does the severity of punishment (Cook 1980; Nagin 2013). In this respect, this article focuses on perceptions of the likeliness of detection for the two types of corrupt behaviors under investigation.

Research into consumer misbehavior and consumer ethics has also mentioned the critical role of personality characteristics in accounting for how people judge misbehaviors (e.g., Daunt and Harris 2011; Erffmeyer et al. 1999; Reynolds and Harris 2009; Rawwas et al. 2005; Wirtz and Kum 2004). Prior research shows that consumers' level of morality relates negatively to consumers' cheating inclinations (Wirtz and Kum 2004). People hold a magnitude range of dishonesty within which they cheat without feeling pressure to update their self-concept due to behavior-induced negative self-signals (Mazar et al. 2008). In addition to that, studies demonstrate that obstructive personality traits, such as Machiavellianism, influence 
consumers' ethics (Rawwas 1996) and consumer misbehavior (Daunt and Harris 2011). Such personality traits, which are facets of the more comprehensive concept of psychological obstructionism, exist before, during, and after an (dysfunctional) exchange and impact the manner in which consumers judge the severity of dysfunctional behaviors (Reynolds and Harris 2009). This article considers two personality traits that reflect individuals' predispositions about how to achieve a high social status: opportunism and ruthlessness, and bribery and corruption. These concepts reflect chronic dispositions and have the potential to shape individuals' interpretations of fraudulent acts. Moreover, these personality traits capture individual differences in personal competitiveness, which has been emphasized as a relevant predictor of consumer misbehavior (Weigel et al. 1987).

Besides deterrence and personality factors, norms have been shown to impact consumers' judgments of misbehavior (e.g., Fullerton and Punj 1993, 2004; Hunt and Vitell 2006; Moschis and Cox 1989). Norms reflect standards of acceptable behavior and guide individuals by posing expectations about how to act in a particular manner in a specific situation. Behavioral expectations can emerge from personal norms that follow from an individual's internalized values, enforced by the anticipation of selfenhancement or self-deprecation (Schwartz 1973), as well as social standards that follow from an individual's perception of common behaviors among members of a reference group in a particular setting (descriptive social norms) and/or perceptions of common (dis-)approval of acceptable behaviors (injunctive social norms) (Cialdini et al. 1990). The collective norms of a society are often mirrored in its actual law which enforces acceptable behavior by legal sanctions (Posner 1997). Legal rules add "to the force of a specific obligational norm, the force of the general norm of obedience to law, which is one of the most powerful norms of society" (Eisenberg 1999, p. 1257). Previous work shows that obedience to law influences individuals' compliance with rules and standards (e.g., Tyler 2001; Weigel et al. 1987). In this respect, this article includes obedience to law into the analysis.

A considerable body of previous work on consumer misbehavior and unethical judgments concentrates on sociodemographic attributes to differentiate between honest and dishonest consumers or to assess effects on consumer ethics (e.g., Babin and Griffin 1995; Cox et al. 1990; Rawwas 1996; Vitell et al. 1991). The findings of these studies indicate that misbehaving consumers cover the entire socioeconomic spectrum (Dawson 1993; Fullerton and Punj 2004). However, studies point to consistent patterns of results for some forms of misbehavior. With regard to shoplifting, studies show that younger students judge shoplifting significantly less wrong than older students or adults (Babin and Griffin 1995). The findings for shoplifting correspond to results with regard to fare dodging. For fare dodging, self-report studies show that this type of corrupt behavior is relatively more common among youth (Weerman 2007) and males (Hauber 1980).

\section{A Complexity Theoretical Perspective on Ethical Judgments}

According to Jones (1991, p. 367), "an ethical decision is defined as a decision that is both legal and morally acceptable to the larger community. Conversely, an unethical decision is either illegal or morally unacceptable to the larger community." The process how individuals make (un)ethical decisions, the factors that influence these decisions, and the behavioral implications that derive from individuals' (un)ethical decisions have been approached from different viewpoints including psychological perspectives (e.g., Hunt and Vitell 1986; Kohlberg 1984; Rest 1986), interpersonal perspectives (e.g., Albert and Horowitz 2009; Albert et al. 2015), and contingency perspectives (e.g., Ferrell and Gresham 1985; Jones 1991; Trevino 1986) among others.

One of the most common approaches used to examine ethical decision making is the cognitive approach (e.g., Hunt and Vitell 1986, 2006; Kohlberg 1984; Rest 1986). Studies adopting this perspective reveal that ethical decision making involves a multi-stage process in which an individual recognizes an ethical issue, makes an ethical judgment, develops an intention to act ethically, and acts on ethical concerns and engages in ethical behavior (Rest 1986). Ethical judgment has been considered as the most critical element in ethical decision making (Albert et al. 2015; Kohlberg 1984) and research into ethical judgment points to two important frameworks that individuals rely on when they make ethical decisions: consequentialism and formalism. Consequentialism refers to end-based decision making, involves teleological evaluations, and focuses on the consequences of an act (Albert et al. 2015; Reynolds 2006). A particular act or behavior is considered as ethical if the evaluation process indicates greater goodness than badness over alternatives (Hunt and Vitell 2006). Formalism refers to obligation-based decision making, involves deontological evaluations, and focuses on the means (i.e., norms and principles) to determine ethicality of an act (Albert et al. 2015; Reynolds 2006). From this perspective, a particular act or behavior is considered as ethical if the evaluation process indicates rightness rather than wrongness (Hunt and Vitell 2006). In many situations, both approaches to ethical judgment will yield similar results (DeGeorge 1999), which is attributable to their inherent complementary nature. For example, Brady (1985) suggests a Janus-headed model of ethical theory, with 
consequentialism (looking into the future) and formalism (looking into the past) representing the two faces that pose simultaneous interests to be addressed by a decision maker.

Besides individuals' ethical predisposition, situational factors, social forces, and opportunity have been identified as relevant contingencies of ethical decision making (Ferrell and Gresham 1985; Trevino 1986). In addition, the ethical issue itself affects ethical judgment and overall decision making. Individuals' responses to ethical issues differ based on the nature of the issue they encounter, especially its moral intensity (Jones 1991). The recently developed Integrated Ethical Decision Making (I-EDM) model by Schwartz (2016) synthesizes these notions and suggests an integrative framework outlining the ethical decision making process, antecedents and subsequences of the process, and factors affecting these processes. It indicates that ethical decision making, and ethical judgment in particular, involves complex processes whose outcome depends on the interplay among a number of factors residing within the individual as well as the situational context.

The central argument of this article is that an enhanced understanding of individuals' ethical judgments may benefit from the analysis of complex causality (Ragin 2008). Rather than asking how much a single antecedent condition such as, for example, a person's obedience to law matters, the study here asks how multiple antecedent conditions work together and combine to configurational causes to matter. This position implies a complexity turn in theorizing and testing and involves examination of complex causality. The primary theoretical lens in this study is that of complexity theory (Byrne and Callaghan 2013; Urry 2005; Woodside 2017), which consists of a set of tenets that concern how elements of a system work together to bringing about an outcome.

Complexity theory holds that causal factors through their interplay develop collective properties or patterns (Urry 2005). Thus, an outcome typically depends on multiple causal factors whose patterning affects the occurrence and nature of the outcome. Conceptually, the patterns of causal factors are viewable as configurations that share a common theme. It follows from this that single causal factors are likely insufficient to bring about an outcome, such as an unethical judgment. What is more important is the recipe, that is, configurational causes to explain unethical judgments. Prior work adopting a contingency perspective lends support for this assumption and indicates that it is the interplay among various factors which influences ethical decision making, with single factors reinforcing or weakening the effects of others, (e.g., Ferrell and Gresham 1985; Jones 1991; Schwartz 2016; Trevino 1986). Proposition 1 is a testable proposition that derives from this perspective.
P1 Single antecedent conditions (deterrence, personality, norm, and sociodemographic factors) are insufficient to explain consumers' unethical judgments of corrupt behaviors consistently, but configurational causes can explain consumers' unethical judgments consistently.

A further tenet of complexity theory is equifinality, that is, alternative configurations of causal factors can produce an outcome. The configurations may differ in their particular compositions, but they eventually lead to the same outcome. Previous work on shoplifting and fare dodging reveals alternative profiles of misbehaving consumers that differ to the extent in which consumers perceive deterrence, hold personal standards, and comply with norms. For example, Cameron (1964), Moore (1984), and Schlueter et al. (1989) describe different profiles of shoplifters and Hauber (1980) reveals different profiles of fare dodgers. Thus, rather than searching for one all-encompassing model that explains the majority of the variation in an outcome, complexity theory and the equifinality notion suggest the occurrence of different configurational causes for attitudes toward corrupt behaviors. Hence, the second proposition reads as follows:

P2 No single best, but multiple configurations of deterrence, personality, norm, and sociodemographic factors explain consumers' unethical judgments of corrupt behaviors.

Complexity theory proposes also the occurrence of asymmetry. Relationships among causal factors "[...] can be non-linear with abrupt switches occurring, so the same 'cause' can, in specific circumstances, produce different effects" (Urry 2005, p. 4). The basic premise underlying this idea is the existence of so-called tipping points (Gladwell 2002), that is, moments when a system passes particular thresholds due to minor changes in its underlying elements, tips, and substantially changes in scope (escalation) and/or composition (alteration of form) (Andersson and Pearson 1999). The cumulative effect of configurational causes of an outcome can emerge from configurations in which single conditions can take opposite roles or turn out as irrelevant. Thus, the third proposition reads as follows:

P3 Across configurational causes for consumers' unethical judgments toward corruptive behaviors, both the presence and the negation of single antecedent conditions (i.e., deterrence, personality, norm, and demographic factors) contribute to the outcome, depending on how the single antecedent conditions form a configurational cause with other antecedent conditions. 


\section{Research Approach}

\section{Empirical Basis and Measures}

To probe the three propositions, this study analyzes data that came from the German General Social Survey (GGSS, GESIS-Leibniz Institute for the Social Sciences 2008). Every 2 years since 1980, a representative cross section of the population is surveyed on attitudes, behaviors, and social structure using both constant and variable questions. The data used in this study came from the survey of the year 2000 , that is, the latest survey which included questions about the corrupt consumer behaviors of interest here. In total, 3804 respondents participated in this survey. However, the GGSS 2000 employs a split-questionnaire survey approach, which means that different respondents receive different sets of survey questions. The basic intuition behind this approach is to capture data on a wide range of topics, while keeping the interview duration at a reasonable level (Koch et al. 2001). For this reason, many respondents did not receive questions regarding the judgment of corrupt behaviors (i.e., our outcome conditions) and some of the antecedent conditions. The analyses were performed for a subset of these cases for which complete responses were available on the antecedent conditions and the outcomes of interest here.

For unethical judgments of corruptive behaviors, respondents evaluated two situations on a four-point Likert-type scale ranging from 1 for "definitely bad" to 4 for "definitely not bad": "Somebody takes goods worth $\$ 25$ from a department store without paying" (shoplifting), and "Somebody uses public transport without buying a valid ticket" (fare dodging). To capture the likeliness of detecting corrupt behaviors, respondents should image they were to take goods from a shop or department store without paying (shoplifting), and they used public transport without having a valid ticket (fare dodging). Respondents evaluated the likeliness of detection for each situation on a five-point Likert-type scale ranging from 1 for "very unlikely" to 5 for "very likely." Regarding the measurement of the personality traits, respondents should rate the relevance of opportunism and ruthlessness and bribery and corruption as means to get to the top of society. Respondents answered these questions on reversely coded four-point Likert-type scales ranging from 1 for "very important" to 4 for "unimportant." The item "One must always obey laws regardless of whether one agrees with them or not" captured obedience to law. Respondents indicated their level of (dis)agreement with this statement on a reversely coded four-point Likert-type scale ranging from 1 for "completely agree" to 4 for "completely disagree." Finally, respondents indicated sociodemographic attributes including gender (male/female), age (in years), household size (total number of persons living in the household), and household income (total net income of the household per month).

Due to the split-questionnaire survey approach, respondents' options to indicate lack of knowledge and non-applicability of questions, and the sensitivity of the subject matter, the dataset reduced to a final sample of 390 valid responses. Of the respondents, $54 \%$ are female and the mean age of the respondents is 48.7 years $(\mathrm{SD}=16.72)$. The average household size is 2.8 persons $(\mathrm{SD}=1.27)$, and the mean net household income per month in national currency is 3950.8 ( $\mathrm{SD}=2216.50)$. We run a series of $t$ tests to identify whether there are significant differences between respondents who are part of our analysis and those respondents who received a question but have been excluded due to missing data. The results of these tests indicate no significant differences between the two groups (i.e., all $p s>.05$ ), except for one antecedent condition. For obedience to law, the results indicate a significant difference $\left(M_{\text {selected }}=3.23, M_{\text {not }}\right.$ selected $=$ $3.35, \Delta M=.12, p<.01)$. Respondents included in our analysis have a slightly lower level of obedience to law in comparison with those who have been excluded.

\section{Data Analysis}

This study employs fsQCA to probe the three propositions. FsQCA is a set-theoretic research approach that views cases as combinations of attributes (i.e., antecedent conditions and outcome conditions) and that builds on the notion that relationships among the attributes are best understood in terms of set membership and set relations (Ragin 2006; 2008). FsQCA describes cases that show desired values for the outcome in question by examining the degree to which antecedent conditions or configurations of these conditions are present. Thus, fsQCA specifies how the membership of cases in sets of causal conditions relates to membership in the outcome set (Ragin 2008). To examine which combinations of antecedent conditions are sufficient for the outcomes, the analysis proceeded in three steps (Fiss 2011; Ragin 2008): calibration of fuzzy sets, construction of the truth tables, and analyses of the truth tables.

\section{Calibration}

Calibration encompasses the definition of fuzzy sets and involves the transformation of construct measures into fuzzy-set membership scores. Through calibration, each case receives fuzzy-set scores that reflect the membership of a case in the antecedent sets and outcome sets under analysis. Fuzzy-set scores can range from 0 (full non- 
membership in a set) to 1 (full membership in a set), with value .5 denoting the crossover point. Full set membership and full set non-membership are qualitative states and the continuum between these two states reflects varying degrees of set membership ranging from "more out" (i.e., scores closer to 0) to "more in" (i.e., scores closer to 1) (Fiss 2011; Ragin 2000, 2008). The crossover point reflects the degree of maximum ambiguity with regard to set membership (i.e., whether a case is in or out of a set). As such, fuzzy-set scores point to differences in kind (i.e., whether or not a case shows a condition) and differences in degree for cases similar in kind (i.e., to what extend a case shows/does not show a condition). FsQCA literature suggests the definition of three anchors to structure the calibration (Ragin 2000): the threshold for full membership in the set, the threshold for full non-membership in the set, and the crossover point.

Consumers' unethical judgments of two corrupt behaviors are the outcomes of interest in this study and were captured on four-point Likert-type rating scales. The scale descriptors served as reference points to calibrate the outcomes. The threshold for full membership in the sets of shoplifting and fare dodging prone consumers was set at 4 (i.e., these respondents judge corrupt behaviors as "definitely not bad"), and the threshold for full non-membership in these sets was set at 1 (i.e., these respondents judge corrupt behaviors as "very bad"). The halfway mark of 2.5 between full membership and full non-membership denoted the crossover point.

Deterrence, personality, norm, and sociodemographic factors are the antecedent conditions to explain judgments of the corruptive behaviors. The fuzzy sets for high perceived likeliness of detecting shoplifting and fare dodging were calibrated using the endpoints and the midpoint of the five-point Likert-type scales. Thus, respondents were fully in the sets if they reported a value of 5 ("very likely") and fully out of the set if they indicated a value of 1 ("very unlikely"). The crossover point was set at value 3 ("about 50:50"). The personality factors opportunism and ruthlessness and bribery and corruption were measured with four-point Likert-type scales. As for the outcomes, respondents were coded as fully in the fuzzy sets if they reported the value 4 ("very important") and they were fully out of the set if they reported the value 1 ("unimportant"). The halfway mark of 2.5 between these thresholds served as the crossover point. Obedience to law was measured on a four-point Likert-type scale as well. Thus, the threshold for full membership in the fuzzy set was set at 4 , the threshold for full non-membership at 1 , and the crossover point was set at 2.5. For gender, this study created a crisp set with men fully in the set (i.e., value 1) and women fully out of the set (value 0 ). For age, this study set the threshold for full membership in the fuzzy set of elderly people at
65 years and the threshold for full non-membership in this set at 25 years (i.e., respondents equal to or younger than 25 years are fully out of the set of elderly people and fully in the set of youths). The crossover point was set at 40 years. The thresholds for the calibration of age correspond to external standards. For example, OECD (2015) defines the elderly population as people aged 65 years and over and OECD (2013) specifies youth as people younger than 25 years. The final sociodemographic factor in this study is equivalized household income (i.e., total net household income per month divided by the square root of the total number of persons living in the household; OECD 2011). This measure rests on the assumption that, for example, a household with four persons has needs twice as large as a single-person household. According to official databases, the mean equivalized household income per month for Germany in 2000 was approximately 3200 DM (LIS 2010). This value served as the crossover point. Thus, respondents indicating an equivalized household income greater than the average household income are more in than out of the high income set and respondents reporting a household income lower than the average score are more out of than in the fuzzy set of high income. This study specified full membership in the set of high income at value 6400 (i.e., two times the mean household income). For full non-membership in the set of high income, this study set the threshold at value 1600 (i.e., half of the average equivalized household income).

Calibration can produce fuzzy-set membership scores of exactly 0.5 . These scores meet the crossover point and thus produce ambiguity regarding a case's membership in a set (Ragin 2008). To address this issue, this study added a constant of .001 to the fuzzy-set membership scores for all conditions below full membership (Fiss 2011). The fs/QCA software program (Ragin and Davey 2016), which includes commands for the calibration of fuzzy sets, helped obtain the fuzzy-set scores for all relevant conditions. Table 1 shows descriptive statistics for all measures and summarizes the calibration rules for the definition of the fuzzy sets.

\section{Construction of the Truth Tables}

The second step of the fsQCA involved the construction of truth tables (Ragin 2008). A truth table is a data matrix that contains $2^{\mathrm{k}}$ rows, where $\mathrm{k}$ denotes the number of antecedent conditions under investigation. Because fsQCA can handle multiple antecedent conditions but only one outcome of interest in an analysis, this study created two truth tables (i.e., one for each judgment). Truth tables need preliminary refinement prior to the analysis based on the two criteria of frequency and consistency (Ragin 2008). Frequency indicates the extent to which the combinations 
Table 1 Descriptive statistics and calibration rules for the fsQCA

\begin{tabular}{|c|c|c|c|c|c|c|c|}
\hline \multirow[t]{2}{*}{ Causal conditions } & \multicolumn{4}{|c|}{ Descriptive statistics } & \multicolumn{3}{|c|}{ Calibration rules } \\
\hline & M & SD & Min & Max & FM & $\mathrm{CP}$ & FNM \\
\hline \multicolumn{8}{|l|}{ Outcome conditions } \\
\hline Unethical judgment of shoplifting & 1.8 & 0.75 & 1 & 4 & 4 & 2.5 & 1 \\
\hline Unethical judgment of fare dodging & 2.4 & 0.82 & 1 & 4 & 4 & 2.5 & 1 \\
\hline \multicolumn{8}{|l|}{ Antecedent conditions } \\
\hline Likeliness of detection of shoplifting & 3.5 & 1.24 & 1 & 5 & 5 & 3 & 1 \\
\hline Likeliness of detection of fare dodging & 3.1 & 1.12 & 1 & 5 & 5 & 3 & 1 \\
\hline Opportunism and ruthlessness & 2.5 & 1.02 & 1 & 4 & 4 & 2.5 & 1 \\
\hline Bribery and corruption & 2.0 & 0.97 & 1 & 4 & 4 & 2.5 & 1 \\
\hline Obedience to law & 3.2 & 0.76 & 1 & 4 & 4 & 2.5 & 1 \\
\hline Gender (male) & - & - & - & - & 1 & - & 2 \\
\hline Age & 48.7 & 16.72 & 18 & 93 & 65 & 40 & 25 \\
\hline Equivalized household income $^{\mathrm{a}}$ & 2581.8 & 1656.60 & 173.21 & 12,500 & 6400 & 3200 & 1600 \\
\hline
\end{tabular}

$M$ mean, $S D$ standard deviation, Min minimum, Max maximum, $F M$ full membership in the set, $C P$ crossover point, FNM full non-membership in the set

${ }^{a}$ Household income divided by the square root of household size of antecedent conditions, as expressed in the rows of a truth table, have empirical representation. The definition of a frequency cutoff ensures that the assessment of the fuzzysubset relations occurs only for those configurations that exceed a minimum level of empirical observation. The basic rationale underlying this idea is that configurations with very few empirical instances might occur due to random forces or measurement errors (Ragin and Fiss 2008). In small- and medium-sized samples frequency, cutoffs of 1 are appropriate; for large-scale samples, frequency cutoffs should be set higher (Ragin 2008). In addition, fsQCA literature recommends that at least $80 \%$ of all of the empirical cases should be part of the analysis (Greckhamer et al. 2013).

Consistency "indicates how closely a perfect subset relation is approximated" (Ragin 2008, p. 44). A subset relation is established if the degree of membership in the antecedent condition set is less than or equal to the degree of membership in the outcome set. Because perfectly consistent subset relations rarely occur in reality, Ragin (2006) recommends a minimum acceptable consistency level of .75. Following this and recommendations by Schneider and Wagemann (2010) who suggest inspection of the ordered consistency values and identification of dips between the values, this study selected consistency thresholds to refine the truth tables for subsequent analyses. Table 2 reports the actual frequency and consistency thresholds used for each analysis.

\section{Analysis of the Truth Tables}

To analyze the truth tables, this study used the fs/QCA software program (version 3.0, Ragin and Davey 2016), employing the Quine-McCluskey algorithm as outlined by Ragin (2008). This algorithm uses Boolean algebra and conducts a counterfactual analysis of what antecedent conditions lead to the outcome in question. The algorithm identifies minimally sufficient (combinations of) antecedent conditions that can bring about an outcome by eliminating those antecedent conditions that are sometimes present and sometimes not present (Fiss 2011 and Thiem and Dusa (2013) for further information on Boolean minimization).

FsQCA reports three types of solutions (i.e., a complex, a parsimonious, and an intermediate solution). Each of these solutions displays pathways to the particular outcome in question. However, the solutions differ to the extent in which logical remainders have been considered (Ragin 2008). Logical remainders are configurations that lack sufficient empirical manifestation (i.e., they are either unobserved or they do not show enough empirical observations to pass the frequency threshold). The complex solution does not consider any logical remainder and thus produces the most complicated result. The parsimonious solution considers any logical remainder that will help generate a logically simpler solution and thus produces the most concise result. The intermediate solution disregards fewer causal conditions than the parsimonious solution but more causal conditions than the complex solution. The intermediate solution thus reports results that represent a compromise between inclusions of no or any logical 
Table 2 Six configurational models indicating unethical judgments of corrupt behaviors

\begin{tabular}{|c|c|c|c|c|c|c|}
\hline & \multicolumn{6}{|c|}{ Unethical judgment of } \\
\hline & \multicolumn{2}{|c|}{ shoplifting } & \multicolumn{4}{|c|}{ fare dodging } \\
\hline & 1 & 2 & 3 & 4 & 5 & 6 \\
\hline Likeliness of detection & • & $\bullet$ & $\bullet$ & $\otimes$ & $\bullet$ & • \\
\hline Opportunism and ruthlessness & $\bullet$ & $\otimes$ & $\otimes$ & - & $\bullet$ & 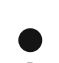 \\
\hline Bribery and corruption & 0 & $\otimes$ & $\otimes$ & & • & \\
\hline Obedience to law & $\otimes$ & $\otimes$ & $\otimes$ & $\bigotimes$ & $\otimes$ & $\otimes$ \\
\hline Gender (male) & $\bigotimes$ & $\otimes$ & $\bigotimes$ & ○ & $\otimes$ & \\
\hline Age & $\otimes$ & & $\otimes$ & $\bigotimes$ & $\bigotimes$ & \\
\hline Household income (eq.) & $\otimes$ & $\otimes$ & $\otimes$ & $\otimes$ & $\otimes$ & $\otimes$ \\
\hline Consistency & .84 & .81 & .96 & .96 & .97 & .97 \\
\hline Raw coverage & .14 & .25 & .11 & .09 & .09 & .10 \\
\hline Unique coverage & .02 & .12 & .04 & .03 & .02 & .04 \\
\hline Overall solution consistency & \multicolumn{2}{|c|}{.78} & \multicolumn{4}{|c|}{.95} \\
\hline Overall solution coverage & \multicolumn{2}{|c|}{.26} & \multicolumn{4}{|c|}{.26} \\
\hline
\end{tabular}

"indicates the presence and " $\otimes$ " indicates the negation of an antecedent condition; big circles indicate core conditions and small circles indicate peripheral conditions; blank spaces indicate conditions with a subordinate role; analysis thresholds for shoplifting: frequency $=3$ ( $86 \%$ of the cases), consistency $=.82$; analysis thresholds for fare dodging: frequency $=3$ ( $85 \%$ of the cases), consistency $=.95$

reminder in the counterfactual analysis. Fiss (2011) suggests focusing on the parsimonious and the intermediate solutions when interpreting the results. Inspection of these solutions provides vision for core and peripheral conditions for an outcome in question. As Fiss (2011, p. 403) points out, "... core conditions are those that are part of both parsimonious and intermediate solutions, and peripheral conditions are those that are eliminated in the parsimonious solution and thus only appear in the intermediate solution." The core/periphery distinction offers insights into causal essentiality of specific antecedent conditions, with peripheral or elaborating conditions surrounding the core elements in configuration and reinforcing their central features (Fiss 2011).

To assess the relative importance of solutions, the fsQCA reports coverage values. Coverage is a proportional measure of the extent to which the solution "explains" the outcome. Coverage indicates the percentage of cases that take a given pathway to the outcome in question (Fiss 2011; Ragin 2000, 2008). Two coverage scores, the raw coverage and the unique coverage, assess empirical importance. Raw coverage refers to the size of the overlap between the size of the antecedent combination set and the outcome set relative to the size of the outcome set; unique coverage controls for overlapping sets by partitioning the raw coverage.

\section{Findings}

Table 2 shows configurations of the multiple antecedent conditions that are consistently sufficient for favorable consumer judgments of corrupt behaviors. The results are summarized using the notation developed by Ragin and Fiss (2008). According to this notation, black circles indicate the presence of an antecedent condition and empty circles indicates its negation. Large circles symbolize core conditions, and small circles denote peripheral conditions. Blank spaces in Table 2 indicate conditions that have a minor role for a solution. That is, these antecedent conditions may be either present or absent and thus have a subordinate role.

The results point to two configurational models for a favorable evaluation of shoplifting (i.e., models 1 and 2) and four configurational models for a favorable evaluation of fare dodging (i.e., models 3-6). 
Regarding the unethical judgment of shoplifting, the overall solution consistency score is .78. The two configurations have consistency scores of .81 (for configuration 1) and of .84 (for configuration 2). Thus, the results indicate two consistently sufficient configurational causes for an unethical appraisal of shoplifting. The overall solution coverage index is .26. Of the two configurations, configuration 2 achieves a higher raw coverage index (values .25) than configuration 1 (value .14), which indicates a higher relative empirical relevance. To illustrate the interpretation of the findings, configuration 1 is discussed in greater detail. Configuration 1 covers young females with a low household income. Surprisingly, these individuals perceive a high likeliness of detecting shoplifting-but they show a high level of opportunism and ruthlessness as well as a high level of bribery and corruption. In addition, these individuals have a weak tendency to obey the law. In model 1 female gender, a strong bribery and corruption predisposition, and a weak obedience to law are core conditions, whereas the remaining antecedent conditions are peripheral factors.

Regarding the unethical judgment of fare dodging, the results show four configurational models with an overall consistency score of .95 . The consistency scores for the particular solutions range between .96 and .97 . The overall solution coverage index is .26 . Of the four configurations for favorable judgments of fare dodging, configuration 3 achieves the highest raw coverage index (i.e., value .11).

In summary, the results of the analyses indicate that no single antecedent condition is consistently sufficient to explain consumers' unethical judgments of corrupt behaviors, but configurations of multiple antecedent conditions, that is, configurational causes can sufficiently explain these judgments with high consistency. These findings supports proposition 1 . In addition, the results of the analyses show the co-existence of alternative configurational causes for both unethical judgments. Thus, different pathways to favorable appraisals of corrupt behaviors exist. This result supports proposition 2, which anticipated the occurrence of multiple effective constellations of antecedent conditions for consumers' unethical judgments of corrupt behaviors. Finally, and as inspections of the particular configurations for the two attitudes indicate, single antecedent conditions can have enhancing effects in one configuration, but detrimental effects in another one. For example, a strong opportunism and ruthlessness disposition is an ingredient in configurations 1 and $4-6$, whereas its negation is an ingredient in configurations 2 and 3. Thus, asymmetrical effects occur, depending on how a particular antecedent condition combines with additional antecedent conditions to form a configurational cause. This finding supports proposition 3 , which anticipated the occurrence of asymmetry.

\section{Discussion}

\section{Theoretical Contributions}

Corrupt consumer behavior poses major challenges for organizations in a wide range of settings. The understanding of the pattern of causal factors that can explain consumers' judgments of those behaviors is thus paramount. The present study takes a step in improving the understanding of consumers' unethical appraisal of two frequent forms of corrupt consumer behavior-shoplifting and fare dodging — by examining underlying configurational causes.

This study contributes to the literature by developing complexity theoretical propositions about how multiple characteristics of individuals form constellations sufficient for predicting and explaining the appraisal of dysfunctional consumer acts. This shift in perspective, the complexity turn, provides new insights into patterns of causal factors for unethical decision making and integrates different theoretical perspectives on the topic. Complexity theory holds that multiple factors work together and form patterns that influence the occurrence and nature of phenomena (e.g., Byrne and Callaghan 2013; Urry 2005; Woodside 2017). The findings of this study demonstrate alternative configurations of deterrence, personality, norm, and sociodemographic factors that are consistently sufficient for favorable judgments of corrupt behaviors.

Knowledge of the configurations improves the understanding of multiple realities (Woodside 2014) and offers nuanced insights into the reasons why people approve and condone corrupt behaviors. For example, Fullerton and Punj (1997) note that the reasons for misbehavior are manifold and can include such aspects as calculating opportunism, absence of moral constraints, or thrill seeking. The configurational causes identified here mirror these reasons and offer additional insights by unraveling their interconnected structures. The findings reveal two models for the unethical judgment of shoplifting and four models for the unethical judgment of fare dodging. While this result points to multiple configurational causes for both unethical judgments, it also indicates a difference in multiplicity of equifinal pathways, which may provide an explanation for the variety in taxonomies of misbehaving consumers. The findings of this study thus enhance extant knowledge about shoplifting and fare dodging, and they add to the existing literature on consumer cheating (e.g., Woodside and Sharma 2017).

Knowledge of the configurations helps also understand how particular antecedent conditions complement and suppress each other, and when a high level or a low level of single antecedent conditions contributes to an outcome of 
interest. For example, the results of the analyses show that a high (configurations $1-3$, and 5 and 6 ) as well as a low perceived likeliness of detection (configuration 4) contribute to favorable assessments of corrupt behaviors. Depending on how likeliness of detection combines with additional causal factors (e.g., with strong opportunism and ruthlessness and bribery and corruption dispositions, and weak obedience to law as shown in configuration 1), tipping points (Gladwell 2002) are passed and unethical judgments emerge. The results obtained by the fsQCA thus improve the understanding of psychographic and sociodemographic factors and their configurational effects on unethical judgments, which has been emphasized as a research priority in the study of consumer ethics (Vitell 2003). This knowledge also contributes to a better understanding of ethical dissolution, that is, a process that occurs when the confluence of factors residing within an individual and his or her environment blur the ethical overtones of a decision (Jackson et al. 2013).

\section{Managerial Implications}

The findings of this study offer several implications for practitioners and policy makers. Knowledge about configurational causes of favorable consumer judgments of corrupt behaviors helps companies, such as retailers or public transportation operators, and governmental authorities understand the underlying motives of consumer misbehavior inclinations. This knowledge forms the basis for enhanced segmentation approaches, the development of activities and campaigns to initiate attitudinal changes, and for the design of control mechanisms to prevent dysfunctional consumer acts.

Segmentation approaches to identify fraud-approving persons that rely on easily measurable characteristics such as sociodemographic characteristics are problematic not only because of discrimination issues but also because of their insufficiency in predicting unethical beliefs. Sufficient causal recipes for fraud-approving persons comprise sociodemographic factors and several additional antecedent conditions such as deterrence, personality, and norm factors. Thus, segmentation based on demographics alone is misleading and problematic and should be avoided. What is more important is the development of mechanisms to detect fraud-approving persons based on configurational causes by, for example, development of training programs to enhance frontline employees' abilities to recognize particular factor configurations.

An additional insight that the findings of this study support relates to the development of educational campaigns to stimulate attitudinal changes. Education has the potential to improve moral development, to strengthen ethical constraints, and to facilitate the unlearning of misbehaviors (e.g., Babin and Babin 1996; Fullerton and Punj 1997). The configurational causes that this study identifies may help educators develop campaigns by pointing to four relevant sets of factors underlying consumers' unethical judgments toward corrupt behaviors and by describing their configurational effects. This knowledge may be helpful in designing situation-tailored programs which may present, for example, role models of functional rather than dysfunctional behaviors. Since such programs require major efforts and imply public education, the findings of this study have implications for non-profit organizations concerned with public education as well.

A third learning point that follows from the findings of this study refers to the design of control mechanisms to prevent corrupt consumer behaviors. Here, prior work suggests deterrence as one of the major approaches to prevent consumer misbehavior (e.g., Fullerton and Punj 1997). According to the findings of this study, people judge corrupt behaviors favorably even if they perceive the likeliness of being caught as high. Potential reasons for this result is that some persons are unaware of deterrence mechanisms, implying that companies should disclose and communicate the actions taken to prevent potential offenses more explicitly, or that some persons are well aware of deterrence mechanisms but take the risk to, for example, experience thrill. However, and as the findings reveal, focus on single deterrence approaches such as, for example, investments into technical equipment (e.g., surveillance systems in retail stores or public transportation facilities) to deter potential frauds will likely be insufficient unless accompanied by actions that appeal to additional factors such as, for example, personality and norm factors. To address these additional ingredients of configurational causes, companies should complement deterrence techniques with additional techniques. For instance, retailers and transportation operators should consider implementing communication activities within their stores and trains, respectively, that portray acceptable consumer behavior, disregard dysfunctional acts, and that annul potential justifications used by misbehaving persons.

\section{Limitations and Avenues for Further Research}

Similar to other studies on corrupt behavior in the marketplace (e.g., Brady et al. 2012; Miyazaki et al. 2009), the present study focuses particularly on psychological factors (and sociodemographic factors) indicating evaluations of corrupt behaviors and does not examine actual corrupt behaviors. Research identifying individuals who actually cheat in laboratory experiments as well as field studies of actual cheating behavior are available in relevant literatures (Ariely 2012; Mazar and Ariely 2006). Missing in the literature are studies examining motivations and additional 
individual characteristics and actual future corrupt behavior of the same individuals. Prior work makes clear that studies on self-reporting of own behavior includes substantial shares of inaccuracies (Nisbett and Wilson 1977; Wegner 2002; Wilson 2002; Woodside and Wilson 2002).

Relying only on explicit statements of motivations is a research limitation given the substantial evidence supporting Wilson's (2002) concise book title, Strangers to Ourselves. Achieving high accuracies in motivations-behavior studies on corrupt behavior likely will require data collection on implicit motivations (McClelland 1980; McClelland et al. 1989; Wegner 2002) and unobtrusive observations of behavior (Webb et al. 1966) - a challenging assignment for future research. Complexity theory supports the perspective that respondents approving shoplifting and fare dodging include some individuals who actually never engage in such behaviors and respondents disapproving the same corrupt practices include some individuals who do engage in these behaviors. Theory and empirical research identifying all four categories of motivation-behavior individuals warrants additional research.

Finally, the data set of this study is from the year 2000 and within the past years a number of macro- and microlevel changes have occurred, affecting general environmental, societal, as well as individual-level characteristics. Thus, research is needed that reproduces this study with more recent data. Related to this point, a further avenue for future studies involves the empirical investigation of consumers' ethical decision making over time. Longitudinal analyses of ethical decision making, and especially ethical judgment, could offer insights into variability of configurational causes of (un)ethical judgments and help uncover and describe incidents that stimulate change-in both positive as well as negative directions.

\section{Compliance with Ethical Standards}

Conflict of interest The authors declare that they have no conflict of interest.

Ethical Approval This article does not contain any studies with human participants performed by any of the authors.

Open Access This article is distributed under the terms of the Creative Commons Attribution 4.0 International License (http://creative commons.org/licenses/by/4.0/), which permits unrestricted use, distribution, and reproduction in any medium, provided you give appropriate credit to the original author(s) and the source, provide a link to the Creative Commons license, and indicate if changes were made.

\section{References}

Albert, L. S., \& Horowitz, L. M. (2009). Attachment styles and ethical behavior: Their relationship and significance in the marketplace. Journal of Business Ethics, 87(3), 299-316.
Albert, L. S., Reynolds, S. J., \& Turan, B. (2015). Turning inward or focusing out? Navigating theories of interpersonal and ethical cognitions to understand ethical decision-making. Journal of Business Ethics, 130(2), 467-484.

Andersson, L. M., \& Pearson, C. M. (1999). Tit for tat? The spiraling effect of incivility in the workplace. Academy of Management Review, 24(3), 452-471.

Ariely, Dan. (2012). The honest truth about dishonesty. New York, NY: HarperCollins.

Babin, B. J., \& Babin, L. A. (1996). Effects of moral cognitions and consumer emotions on shoplifting intentions. Psychology and Marketing, 13(8), 785-802.

Babin, B. J., \& Griffin, M. (1995). A closer look at the influence of age on consumer ethics. In F. R. Kardes \& M. Sujan (Eds.), Advances in consumer research, XXII (pp. 668-673). Provo, UT: Association for Consumer Research.

Bellur, V. V. (1981). Shoplifting: Can it be prevented? Journal of the Academy of Marketing Science, 9(1-2), 78-87.

Bijleveld, C. (2007). Fare dodging and the strong arm of the law. Journal of Experimental Criminology, 3(2), 183-199.

Brady, F. N. (1985). A Janus-headed model of ethical theory: Looking two ways at business/society issues. Academy of Management Review, 10(3), 568-576.

Brady, M. K., Voorhees, C. M., \& Brusco, M. J. (2012). Service sweethearting: Its antecedents and customer consequences. Journal of Marketing, 76(2), 81-98.

Byrne, D., \& Callaghan, G. (2013). Complexity theory and the social sciences: The state of the art. London: Routledge.

Cameron, M. O. (1964). The booster and the snitch: Department store shoplifting. New York, NY: Free Press of Glencoe.

Cialdini, R. B., Reno, R. R., \& Kallgren, C. A. (1990). A focus theory of normative conduct: Recycling the concept of norms to reduce littering in public places. Journal of Personality and Social Psychology, 58(6), 1015-1026.

Clarke, R. V., Contre, S., \& Petrossian, G. (2010). Deterrence and fare evasion: Results of a natural experiment. Security Journal, 23(1), 5-17.

Cole, C. A. (1989). Deterrence and consumer fraud. Journal of Retailing, 65(1), 107-120.

Cook, P. J. (1980). Research in criminal deterrence: Laying the groundwork for the second decade. In N. Morris \& M. Tonry (Eds.), Crime and justice: A review of the research (Vol. 2, pp. 211-268). Chicago, IL: University of Chicago Press.

Cox, A. D., Cox, D., Anderson, R. D., \& Moschis, G. P. (1993). Research note: Social influences on adolescent shopliftingTheory, evidence, and implications for the retail industry. Journal of Retailing, 69(2), 234-246.

Cox, D., Cox, A. D., \& Moschis, G. P. (1990). When consumer behavior goes bad: An investigation of adolescent shoplifting. Journal of Consumer Research, 17(2), 149-159.

Daunt, K. L., \& Harris, L. C. (2011). Customers acting badly: Evidence from the hospitality industry. Journal of Business Research, 64(10), 1034-1042.

Daunt, K. L., \& Harris, L. C. (2012). Motives of dysfunctional customer behavior: An empirical study. Journal of Services Marketing, 26(4), 293-308.

Dawson, S. (1993). Consumer responses to electronic article surveillance alarms. Journal of Retailing, 69(3), 353-362.

DeGeorge, R. T. (1999). Business ethics. Upper Saddle River, NJ: Prentice-Hall.

Egan, V., \& Taylor, D. (2010). Shoplifting, unethical consumer behaviour, and personality. Personality and Individual Differences, 48(8), 878-883.

Eisenberg, M. A. (1999). Corporate law and social norms. Columbia Law Review, 99(5), 1253-1292. 
Erffmeyer, R. C., Keillor, B. D., \& LeClair, D. T. (1999). An empirical investigation of Japanese consumer ethics. Journal of Business Ethics, 18(1), 35-50.

Ferrell, O. C., \& Gresham, L. G. (1985). A contingency framework for understanding ethical decision making in marketing. Journal of Marketing, 49(3), 87-96.

Fisk, R., Grove, S., Harris, L. C., Keeffe, D. A., Daunt, K. L., RussellBennett, R., et al. (2010). Customers behaving badly: A state of the art review, research agenda and implications for practitioners. Journal of Services Marketing, 24(6), 417-429.

Fiss, P. C. (2011). Building better causal theories: A fuzzy set approach to typologies in organization research. Academy of Management Journal, 54(2), 393-420.

Fullerton, R. A., \& Punj, G. (1993). Choosing to misbehave: A structural model of aberrant consumer behavior. In L. McAlister \& M. L. Rothschild (Eds.), Advances in consumer research, $X X$ (pp. 570-574). Provo, UT: Association for Consumer Research.

Fullerton, R. A., \& Punj, G. (1997). Can consumer misbehavior be controlled? A critical analysis of two major control techniques. In M. Brucks \& D. J. MacInnis (Eds.), Advances in consumer research, XXIV (pp. 340-344). Provo, UT: Association for Consumer Research.

Fullerton, R. A., \& Punj, G. (2004). Repercussions of promoting an ideology of consumption: Consumer misbehavior. Journal of Business Research, 57(11), 1239-1249.

GESIS-Leibniz Institute for the Social Sciences. (2008). German General Social Survey-ALLBUS 2000-CAPI-PAPI. GESIS Data Archive, Cologne. ZA3755 Data file Version 1.0.0.

Gladwell, M. (2002). The tipping point: How little things can make a big difference. Boston, MA: Little, Brown and Company.

Global Retail Theft Barometer. (2015). The new barometer 2014-2015. Thorofare, NJ: Checkpoint Systems, Inc.

Greckhamer, T., Misangyi, V. F., Elms, H., \& Lacey, R. (2008). Using QCA in strategic management research: An examination of combinations of industry, corporate, and business unit effects. Organizational Research Methods, 11(4), 695-726.

Greckhamer, T., Misangyi, V. F., \& Fiss, P. C. (2013). The two QCAs: From a small-N to a large-N set theoretic approach. In P. C. Fiss, B. Cambré, \& A. Marx (Eds.), Configurational theory and methods in organizational research (pp. 49-75). Bingley: Emerald Group Publishing Limited.

Harris, L. C., \& Daunt, K. (2013). Managing customer misbehavior: Challenges and strategies. Journal of Services Marketing, 27(4), 281-293.

Hauber, A. R. (1980). Daily life and the law: Discrepancies in behavior. International Journal of Law and Psychiatry, 3(2), 187-192.

Hunt, S. D., \& Vitell, S. (1986). A general theory of marketing ethics. Journal of Macromarketing, 6(1), 5-16.

Hunt, S. D., \& Vitell, S. J. (2006). The general theory of marketing ethics: A revision and three questions. Journal of Macromarketing, 26(2), 143-153.

Jackson, R. W., Wood, C. M., \& Zboja, J. J. (2013). The dissolution of ethical decision-making in organizations: A comprehensive review and model. Journal of Business Ethics, 116(2), 233-250.

Jones, T. M. (1991). Ethical decision making by individuals in organizations: An issue-contingent model. Academy of Management Review, 16(2), 366-395.

Kallis, M. J., \& Vanier, D. J. (1985). Consumer shoplifting: Orientations and deterrents. Journal of Criminal Justice, 13(5), $459-473$.

Koch, A., Wasmer, M., \& Scholz, E. (2001). Konzeption und Durchführung der "Allgemeinen Bevölkerungsumfrage der Sozialwissenschaften" (ALLBUS) 2000. ZUMA Methodenbericht $01 / 05$.
Kohlberg, L. (1984). The psychology of moral development: The nature and validity of moral stages. New York, NY: Harper \& Row.

Krasnovsky, T., \& Lane, R. C. (1998). Shoplifting: A review of the literature. Aggression and Violent Behavior, 3(3), 219-235.

Kraut, R. E. (1976). Deterrent and definitional influences on shoplifting. Social Problems, 23(3), 358-368.

LIS-Cross National Data Center in Luxembourg. (2010). Inequality and poverty key figures. Retrieved from http://www.lisdatacen ter.org/lis-ikf-webapp/app/search-ikf-figures.

Lovelock, C. H. (2001). Services marketing: People, technology, strategy (4th ed.). Upper Saddle River, NJ: Prentice-Hall.

Mazar, N., Amir, O., \& Ariely, D. (2008). The dishonesty of honest people: A theory of self-concept maintenance. Journal of Marketing Research, 45(6), 633-644.

Mazar, N., \& Ariely, D. (2006). Dishonesty in everyday life and its policy implications. Journal of Public Policy \& Marketing, 25(1), 117-126.

McClelland, D. C. (1980). Motive dispositions: The merits of operant and respondent measures. In L. Wheeler (Ed.), Review of personality and social psychology (Vol. 1, pp. 10-41). Beverly Hills, CA: Sage.

McClelland, D. C., Koestner, R., \& Weinberger, J. (1989). How do self-attributed and implicit motives differ? Psychological Review, 96(4), 690-702.

Miyazaki, A. D., Rodriguez, A. A., \& Langenderfer, J. (2009). Price, scarcity, and consumer willingness to purchase pirated media products. Journal of Public Policy \& Marketing, 28(1), 71-84.

Moore, R. H. (1984). Shoplifting in middle America: Patterns and motivational correlates. International Journal of Offender Therapy and Comparative Criminology, 28(1), 53-64.

Moschis, G. P., \& Cox, D. (1989). Deviant consumer behavior. In T. K. Srull (Ed.), Advances in consumer research, XVI (pp. 732-737). Provo, UT: Association for Consumer Research.

Nagin, D. S. (2013). Deterrence: A review of the evidence by a criminologist for economists. Annual Review of Economics, 5(1), 83-105.

Nisbett, R. E., \& Wilson, T. D. (1977). Telling more than we can know: Verbal reports on mental processes. Psychological Review, 84(3), 231-259.

OECD. (2011). Divided we stand -Why inequality keeps rising. Paris: OECD Publishing.

OECD. (2013). The OECD action plan for the youth. Retrieved from http://www.oecd.org/newsroom/Action-plan-youth.pdf.

OECD. (2015). Elderly population. Retrieved from http://data.oecd. org/pop/elderly-population.htm.

Posner, R. A. (1997). Social norms and the law: An economic approach. American Economic Review, 87(2), 365-369.

Ragin, C. C. (2000). Fuzzy-set social science. Chicago, IL: University of Chicago Press.

Ragin, C. C. (2006). Set relations in social research: Evaluating their consistency and coverage. Political Analysis, 14(3), 291-310.

Ragin, C. C. (2008). Redesigning social inquiry: Fuzzy sets and beyond. Chicago, IL: University of Chicago Press.

Ragin, C. C., \& Davey, S. (2016). Fuzzy-set/qualitative comparative analysis 3.0. Irvine, CA: Department of Sociology, University of California.

Ragin, C. C., \& Fiss, P. C. (2008). Net effects analysis versus configurational analysis: An empirical demonstration. In C. C. Ragin (Ed.), Redesigning social inquiry: Fuzzy sets and beyond (pp. 190-212). Chicago, IL: University of Chicago Press.

Rawwas, M. Y. (1996). Consumer ethics: An empirical investigation of the ethical beliefs of Austrian consumers. Journal of Business Ethics, 15(9), 1009-1019.

Rawwas, M. Y., Swaidan, Z., \& Oyman, M. (2005). Consumer ethics: A cross-cultural study of the ethical beliefs of Turkish and 
American consumers. Journal of Business Ethics, 57(2), 183-195.

Rest, J. R. (1986). Moral development: Advances in research and theory. New York, NY: Praeger.

Reynolds, S. J. (2006). Moral awareness and ethical predispositions: Investigating the role of individual differences in the recognition of moral issues. Journal of Applied Psychology, 91(1), 233-243.

Reynolds, K. L., \& Harris, L. C. (2009). Dysfunctional customer behavior severity: An empirical examination. Journal of Retailing, 85(3), 321-335.

Schlueter, G. R., O’Neal, F. C., Hickey, J., \& Seiler, G. L. (1989). Rational vs. nonrational shoplifting types; The implications for loss prevention strategies. International Journal of Offender Therapy and Comparative Criminology, 33(3), 227-239.

Schneider, C. Q., \& Wagemann, C. (2010). Standards of good practice in qualitative comparative analysis (QCA) and fuzzysets. Comparative Sociology, 9(3), 397-418.

Schwartz, S. H. (1973). Normative explanations of helping behavior: A critique, proposal, and empirical test. Journal of Experimental Social Psychology, 9(4), 349-364.

Schwartz, M. S. (2016). Ethical decision-making theory: An integrated approach. Journal of Business Ethics, 139(4), $755-776$.

Smith, M. J., \& Clarke, R. V. (2000). Crime and public transport. In M. Tonry \& N. Morris (Eds.), Crime and justice: A review of the research (Vol. 6, pp. 169-233). Chicago, IL: University of Chicago Press.

Suquet, J. B. (2010). Drawing the line: How inspectors enact deviant behaviors. Journal of Services Marketing, 24(6), 468-475.

Thiem, A., \& Duşa, A. (2013). Boolean minimization in social science research: A review of current software for Qualitative Comparative Analysis (QCA). Social Science Computer Review, $31(4), 505-521$.

Tonglet, M. (2002). Consumer misbehaviour: An exploratory study of shoplifting. Journal of Consumer Behaviour, 1(4), 336-354.

Trevino, L. K. (1986). Ethical decision making in organizations: A person-situation interactionist model. Academy of Management Review, 11(3), 601-617.

Tyler, T. R. (2001). Public trust and confidence in legal authorities: What do majority and minority group members want from the law and legal institutions? Behavioral Sciences \& the Law, $19(2), 215-235$
Urry, J. (2005). The complexity turn. Theory, Culture \& Society, 22(5), $1-14$.

Vitell, S. J. (2003). Consumer ethics research: Review, synthesis and suggestions for the future. Journal of Business Ethics, 43(1-2), $33-47$.

Vitell, S. J., Lumpkin, J. R., \& Rawwas, M. Y. (1991). Consumer ethics: An investigation of the ethical beliefs of elderly consumers. Journal of Business Ethics, 10(5), 365-375.

Webb, E. J., Campbell, D. T., Schwartz, R. D., \& Sechrest, L. (1966). Unobtrusive measures: Nonreactive research in the social sciences (Vol. 111). Chicago, IL: Rand McNally.

Weerman, F. M. (2007). Juvenile offending. In M. Tonry \& C. Bijleveld (Eds.), Crime and justice: Crime and justice in the Netherlands (Vol. 35, pp. 261-318). Chicago, IL: University of Chicago Press.

Wegner, D. M. (2002). The illusion of conscious will. Cambridge, MA: Bradford Books, MIT Press.

Weigel, R. H., Hessing, D. J., \& Elffers, H. (1987). Tax evasion research: A critical appraisal and theoretical model. Journal of Economic Psychology, 8(2), 215-235.

Wilson, T. D. (2002). Strangers to ourselves: Discovering the adaptive unconscious. Cambridge, MA: Belknap Press of Harvard University Press.

Wirtz, J., \& Kum, D. (2004). Consumer cheating on service guarantees. Journal of the Academy of Marketing Science, 32(2), 159-175.

Wirtz, J., \& McColl-Kennedy, J. R. (2010). Opportunistic customer claiming during service recovery. Journal of the Academy of Marketing Science, 38(5), 654-675.

Woodside, A. G. (2014). Embrace perform model: Complexity theory, contrarian case analysis, and multiple realities. Journal of Business Research, 67(12), 2495-2503.

Woodside, A. G. (2017). The complexity turn: Cultural, management, and marketing applications. Berlin: Springer.

Woodside, A. G., \& Sharma, M. (2017). Case-based modeling of prolific liars and constant truth-tellers: Who are the dishonesty and honesty self-reporters? Journal of Business Research, 71, $142-153$.

Woodside, A. G., \& Wilson, E. J. (2002). Respondent inaccuracy. Journal of Advertising Research, 42(5), 7-18. 